Check for updates

Cite this: RSC Adv., 2019, 9, 1895

Received 17th October 2018

Accepted 5th January 2019

DOI: $10.1039 / \mathrm{c} 8 \mathrm{ra0} 8603 f$

rsc.li/rsc-advances

\section{Electropolymerization of thienyl tethered comonomers and application towards the electrocatalytic reduction of nitrobenzene $\uparrow$}

\author{
Abbasriyaludeen Abdul Raheem, ${ }^{\text {ac }}$ Sivalingam Gopi, ${ }^{b}$ Murugavel Kathiresan (iD *bc \\ and Chandrasekar Praveen (iD *ac
}

\begin{abstract}
The synthesis of different $\pi$-spacered thiophene comonomers via Suzuki cross-coupling in good synthetic yields was accomplished. Potentiodynamic electropolymerization of these precursors on ITO electrode by constant potential electrolysis results in the deposition of thin films of polymers between 0.05 and $0.2 \mu \mathrm{M}$. Interestingly, the as synthesized $\pi$-conjugated polymers exhibit electrochromic behaviour upon electrochemical oxidation. On the application side, the synthesized electropolymers showed catalytic activity better than glassy carbon towards electrochemical reduction of nitrobenzene.
\end{abstract}

\section{Introduction}

Considerable interest lies in conjugated polymers due to their unique properties such as planarity, semi-conductivity, optical band gap and so on. ${ }^{\mathbf{1}}$ These properties in turn influence their potential applications in organic field effect transistors, actuators, organic light-emitting diodes, organic photovoltaics, etc. ${ }^{2}$ Molecular engineering allows precise tuning of the band gap by proper introduction of functionalities at the side chains. ${ }^{3}$ In addition, doping of external impurities with $\pi$-conjugated polymers is shown to enhance the electronic conductivity. ${ }^{4}$ Chemical method is quite often used to prepare polymer on large scale, but to study the electronic conductivity and/or electrochromic behaviour, deposition of polymer into a conducting matrix becomes necessary. ${ }^{5}$ In this regard, electrochemical polymerisation technique offer advantages such as synthesis under mild conditions, deposition of polymer directly onto the conducting substrate (electrode) and consequent electrochemical characterization of the deposited polymer. ${ }^{6}$ Electrochemical polymerization is frequently used for the synthesis of conducting polymers which show electrochromic behaviour. Thiophene and their derivatives were extensively investigated as monomers for electropolymerization over conducting substrates. ${ }^{7}$ Because of the electron rich C2-position,

${ }^{a}$ Functional Materials Division, Central Electrochemical Research Institute (CSIR Laboratory), Karaikudi-630003, Tamil Nadu, India. E-mail: chandrasekar.praveen@ gmail.com

${ }^{b}$ Electroorganic Division, Central Electrochemical Research Institute (CSIR Laboratory), Karaikudi-630003, Tamil Nadu, India.E-mail: kathiresan@cecri.res.in ${ }^{c}$ Academy of Scientific and Innovative Research (AcSIR), Karaikudi-630003, Tamil Nadu, India

$\dagger$ Electronic supplementary information (ESI) available: Copies of ${ }^{1} \mathrm{H}$ NMR, ${ }^{13} \mathrm{C}$ NMR spectra of monomers, FTIR, UV-vis, PL, SEM and AFM images of polymers. See DOI: 10.1039/c8ra08603f thiophene under electrochemical conditions undergoes a facile one electron oxidation to give highly reactive thiophene radical which is highly prone to polymerisation. Generally, electropolymerization is highly influenced by the solvent media and supporting electrolyte. ${ }^{8}$ Polymers electrosynthesized in different media or supporting electrolyte are shown to have different morphology. ${ }^{9}$ In some cases, supporting electrolytes are used as doping agents as well. Researchers have used this strategy to prepare thiophene polymers, copolymers and doped polymers to fine-tune their electronic properties. ${ }^{10}$ In this context, synthesis of thienyl based hybrid comonomers which are prone to undergo oxidative polymerization becomes essential as it would offer new electrochromic material with varying degree of physicochemical characteristics. ${ }^{11}$ As part of our research interest on small and macromolecular functional organic materials,${ }^{12}$ we herein disclose the synthesis of thienyl end-capped hybrid monomers and their electropolymerization. Results pertaining to photophysical/electrochemical properties of the as prepared polymers, their surface morphology and application in catalytic reduction of nitroarenes are presented in this paper.

\section{Results and discussion}

\section{Monomers synthesis and electropolymerization}

We initiated the synthesis of monomers by subjecting several di-halo aryls/heteroaryls (1a-f) with 3-hexylthiophene-2-boronic acid pinacol ester (2) under typical Suzuki-Miyaura conditions (Scheme 1). As provided in Table 1, all substrates essentially undergo cross-coupling at same conditions to afford good to excellent yields of 3-hexylthiophene end-capped monomers (3ah). Keeping in mind that $\pi$-conjugated polymers possessing carbazole functionalized at the N-position exhibits unique electrochromic properties, ${ }^{13}$ we initially prepared three 

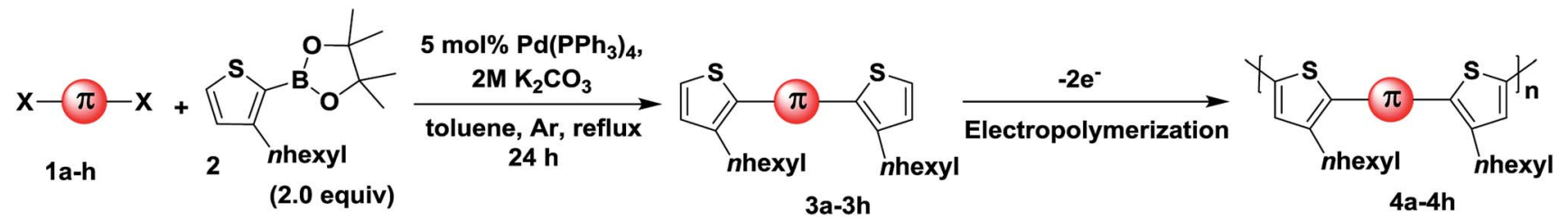

Scheme 1 Suzuki coupling of dihalo- $\pi$-spacers $1 \mathrm{a}-\mathrm{h}$ with 3 -hexylthiophene boronic acid 2.

carbazole based monomers (3a, $\mathbf{3 b}$ and $\mathbf{3 f}$ ). This was followed by the synthesis of monomers with aromatic spacers such as azulenyl, phenyl and biphenyl (3c-e). Finally, precursors having fused thiophene systems were $(\mathbf{3 g}$ and $\mathbf{3 h}$ ) prepared under identical reaction conditions. The presence of two hexyl chains in all monomers enhanced their solubility even in non-polar solvents. All synthesized monomers were purified by flash column chromatography in good to excellent yields and characterized by FTIR, ${ }^{1} \mathrm{H}-\mathrm{NMR},{ }^{13} \mathrm{C}$-NMR spectroscopy.

Having obtained the monomers in satisfactory yields, we next intended the electrochemical polymerisation of the prepared monomers. It is to be remembered that

Table 1 Synthesis and chemical yield of monomers $3 a-f$

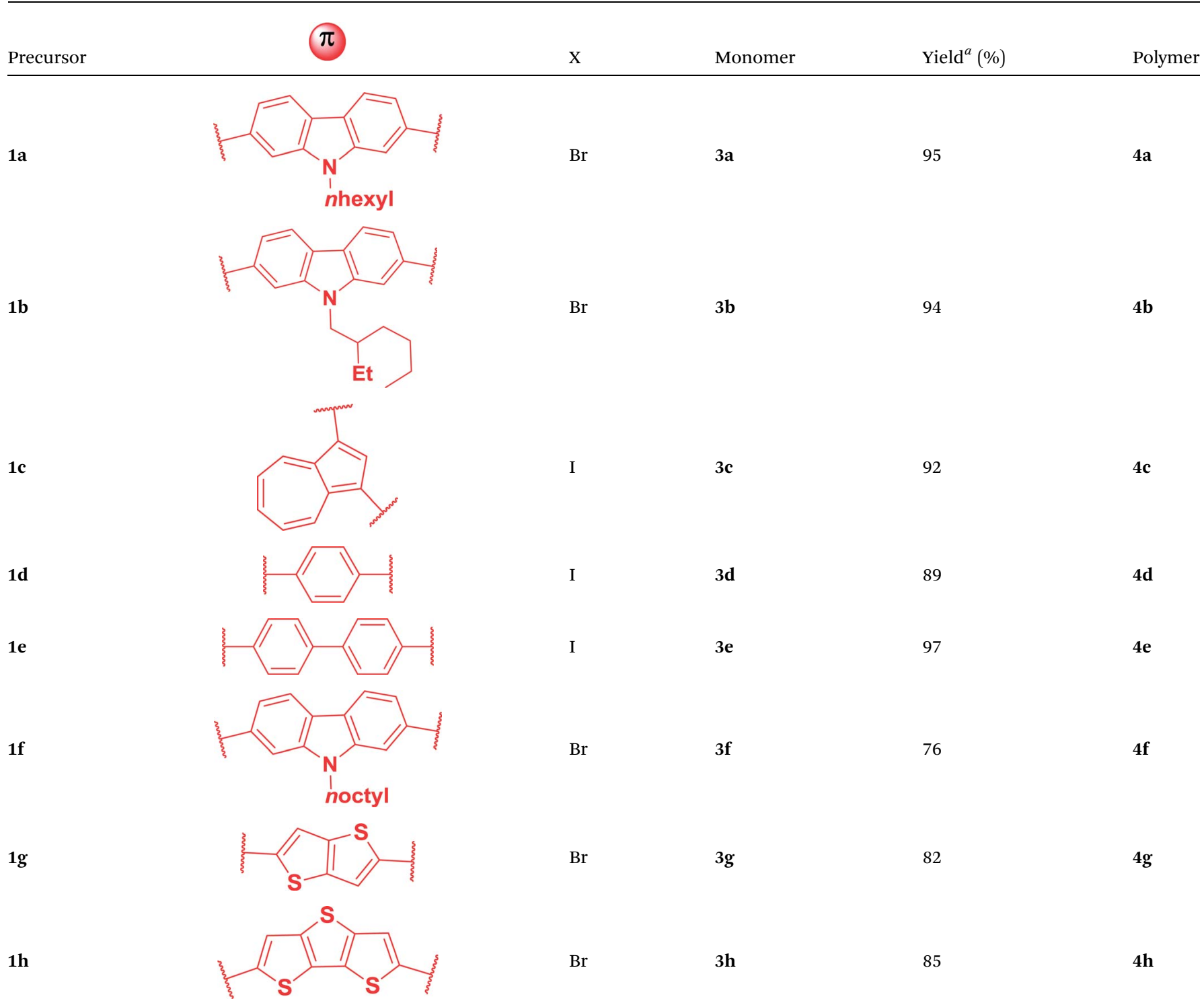

\footnotetext{
${ }^{a}$ Isolated yield after column chromatography and characterized by IR, ${ }^{1} \mathrm{H}$ NMR, ${ }^{13} \mathrm{C}$ NMR and MS.
} 
electrochemical strategy allows for the preparation of uniform thin films of thiophene/substituted-thiophene polymers on conducting substrates (as working electrode in monomer/ electrolyte mixtures), the use of any catalysts can be circumvented. To this end, substituted thiophene polymers were synthesized by employing electrochemical oxidation method as shown in Scheme 1 . The $\pi$ spacer includes carbazole having alkyl chains such as $n$-hexyl (4a), 2-ethylhexyl (4b) $n$-octyl (4f) in addition to azulene (4c), phenyl (4d), biphenyl (4e), thienothiophene $(\mathbf{4 g})$ and dithienothiophene $(\mathbf{4 h})$ units. Since the monomer contains aromatic/heteroaromatic units, upon polymerisation it is expected to give rigid linear polymer which in turn would render poor solubility. To overcome this, we have pre-introduced hexyl units on C3-position of thiophene adjacent to the $\pi$-spacer. Despite these attempts, we obtained thin films of polymer on ITO with poor solubility. Initially, the monomers were characterized by cyclic voltammetry (Fig. S1†). Based on the oxidation potential obtained, multiscan CV was recorded on glassy carbon electrode (Fig. 1). In addition, constant potential electrolysis was carried out on ITO electrode at a fixed potential which is usually $+200 \mathrm{mV}$ higher than that of their corresponding oxidation potential. After obtaining uniform polymer films, the ITO electrode was rinsed with acetonitrile to remove any unreacted monomer impurities. The electrochemical characterisation of the polymer thin films was then carried out in $n \mathrm{Bu}_{4} \mathrm{PF}_{6}(0.1 \mathrm{M})$ in dichloromethane, which revealed the possible electrochromic features of these samples (Fig. S2 $\dagger$ ). All the polymer samples showed electrochromic behaviour when electrochemically oxidized. The colour intensity of the polymers varied which is a consequence of differences in their $\pi$-substituent. When the polymer films are electrochemically reduced, the colour once again disappeared revealing their electrochromic nature. Moreover, a significant increase in the $\mathrm{C}-\mathrm{C}$ stretching and decrease in the $\mathrm{C}-\mathrm{H}$ stretching bands compared to the respective monomers clearly suggests the formation of polymers (Fig. S3†).

\section{Photophysical properties}

As depicted in Fig. 2, electronic absorption and emission spectra of all monomers $(\mathbf{3 a}-\mathbf{h})$ were investigated as tetrahydrofuran solution $\left(5 \times 10^{-5} \mathrm{M}\right)$ and the obtained optical data was disclosed in Table 2. At the outset, UV-vis absorption spectra of all monomers displayed $\pi-\pi *$ transition between 295 and $329 \mathrm{~nm}$ with molar absorptivity $(\varepsilon)$ ranging between 29000 to $49200 \mathrm{M}^{-1} \mathrm{~cm}^{-1}$ (Fig. 2a). Structurally similar carbazole monomers (3a, 3b and $\mathbf{3 f}$ ) showed an identical peak maxima and optical absorption edge $\left(\lambda_{\max } / \lambda_{\text {edge }}=329 / 374 \mathrm{~nm}\right)$. The azulene containing monomer 3c showed a typical stretched wavelength $\left(\lambda_{\text {edge }}=417 \mathrm{~nm}\right)$ characteristic of thienyl-adjoined azulene system. ${ }^{\mathbf{1 4}}$ For benzenoid systems, it was observed that those containing phenyl ring exhibited higher $\varepsilon$ (46500 $\left.\mathrm{M}^{-1} \mathrm{~cm}^{-1}\right)$ and stretched wavelength $\left(\lambda_{\max } / \lambda_{\text {edge }}=309 /\right.$ $352 \mathrm{~nm}$ ). In comparison, the biphenyl counterpart 3e showed significant blue shift $\left(\lambda_{\text {max }} / \lambda_{\text {edge }}=298 / 338 \mathrm{~nm}\right)$ with reduced $\varepsilon$ (29 $000 \mathrm{M}^{-1} \mathrm{~cm}^{-1}$ ). This distinctive behaviour can be attributed to the reduced conjugation effect offered by the different dihedral angle along the thiophene-phenyl and phenyl-phenyl plane. ${ }^{15}$ As expected, those monomers possessing fused thiophene units (3g and $\mathbf{3 h}$ ) displayed fairly high $\varepsilon$ values (136 000 and $239900 \mathrm{M}^{-1} \mathrm{~cm}^{-1}$ ) and reduced band gap (3.06 and 2.93 $\mathrm{eV}$ ), which could be reasoned to their better planarity and extensive $\pi$-delocalization. To assess the solid state aggregation properties, thin film UV-vis spectra were recorded by drop casting THF solution of monomers on quartz plate (Fig. $\mathrm{S} 4 \dagger$ ). All monomers revealed a slightly reduced optical band gap $\left(E_{\mathrm{g}}^{\text {opt }}=\right.$ 2.35 to $3.55 \mathrm{eV})$ compared to their solution state spectra $\left(E_{\mathrm{g}}^{\mathrm{opt}}=\right.$ 2.93 to $3.66 \mathrm{eV}$ ), which might be due to the likely $J$-aggregation in solid state. In comparison, the UV-vis spectra of polymers 4ah (Fig. S5 $\dagger$ ) recorded in THF : $\mathrm{CH}_{2} \mathrm{Cl}_{2}(1: 1)$ exhibit an extended wavelength by showing band gap $\left(E_{\mathrm{g}}^{\mathrm{opt}}=2.13\right.$ to $\left.2.86 \mathrm{eV}\right)$ much lesser than the respective monomers $\left(E_{\mathrm{g}}^{\mathrm{opt}}=2.97\right.$ to $\left.3.66 \mathrm{eV}\right)$. This reduced band gap clearly indicates the possibility of increased $\pi$-conjugation as in the case of semiconducting polymers by extending the optical absorption edge. On the other hand, photoluminescence spectra of monomers as THF solution $\left(5 \times 10^{-5} \mathrm{M}\right)$ showed emission maxima $\left(\lambda_{\mathrm{em}}\right)$ between 387 and $458 \mathrm{~nm}$ with significant Stokes shift ranging from 5300 to $11300 \mathrm{~cm}^{-1}$ with the highest being for 3c (Fig. 2b). It is pertinent to mention that $3 c$ showed a very weak $\mathrm{S}_{1}-\mathrm{S}_{0}$ fluorescence, hence its peak was normalized manifold. ${ }^{16}$ Likewise, the emission spectra of polymers suspended in a 1:1 mixture of THF : $\mathrm{CH}_{2} \mathrm{Cl}_{2}$ were recorded (Fig. S6 $\dagger$ ). The polymers displayed batho/hypsochromic shift in their emission spectra with $\lambda_{\mathrm{em}}$ varying from 387 to $546 \mathrm{~nm}$. This can be reasoned to the varying degree of $\pi-\pi$ interactions of the polymer backbone resulting in low/high energy emissions. For instance, polymers 4a, 4c, 4g and $\mathbf{4 h}$ exhibited Stokes shift of 550, 2000, 5200 and $5000 \mathrm{~cm}^{-1}$ respectively (Table $\mathrm{S} 1 \dagger$ ). Whereas, all other polymers showed substantial anti-Stokes shift $(\mathbf{4 b}=2900 ; \mathbf{4 d}=3500 ; \mathbf{4 e}=4100$ and $\mathbf{4 f}=3200 \mathrm{~cm}^{-1}$ ). This irregular energy dissipation of these polymers can be attributed to the different relaxation delay to the lowest vibrational level of the first excited state $\left(\mathrm{S}_{1}\right)$.

\section{Surface morphology and polymers thickness}

The as synthesized electropolymers $\mathbf{4 a - h}$ were subjected to SEM analysis and all samples revealed different morphology and porosity (Fig. S7†). As evident from the SEM images, most of these polymer samples revealed porous network structure which could result from the subsequent in and out movement of electrolytes during the redox process. For instance, SEM of polymer 4a reveals that the polymer exhibits porous network structure with cauliflower like morphology. Polymer $\mathbf{4 b}$ reveals the micro-porosity and exhibits an accumulation state of clusters of random granules. Polymer 4c was obtained as a welladhered polymer film whose surface was smooth and homogeneous. However, polymer 4d appeared to be irregularly shirked smooth surface with multiple pores on it. Polymer 4 e exhibited a homogeneous and porous structure. At low resolution, it is evident that there is an accumulation of small globules with dense holes among the clusters. However, at higher resolution, plenty of tiny holes were observed on globular surfaces indicating the microporous nature of the sample. Polymer $4 \mathbf{f}$ 

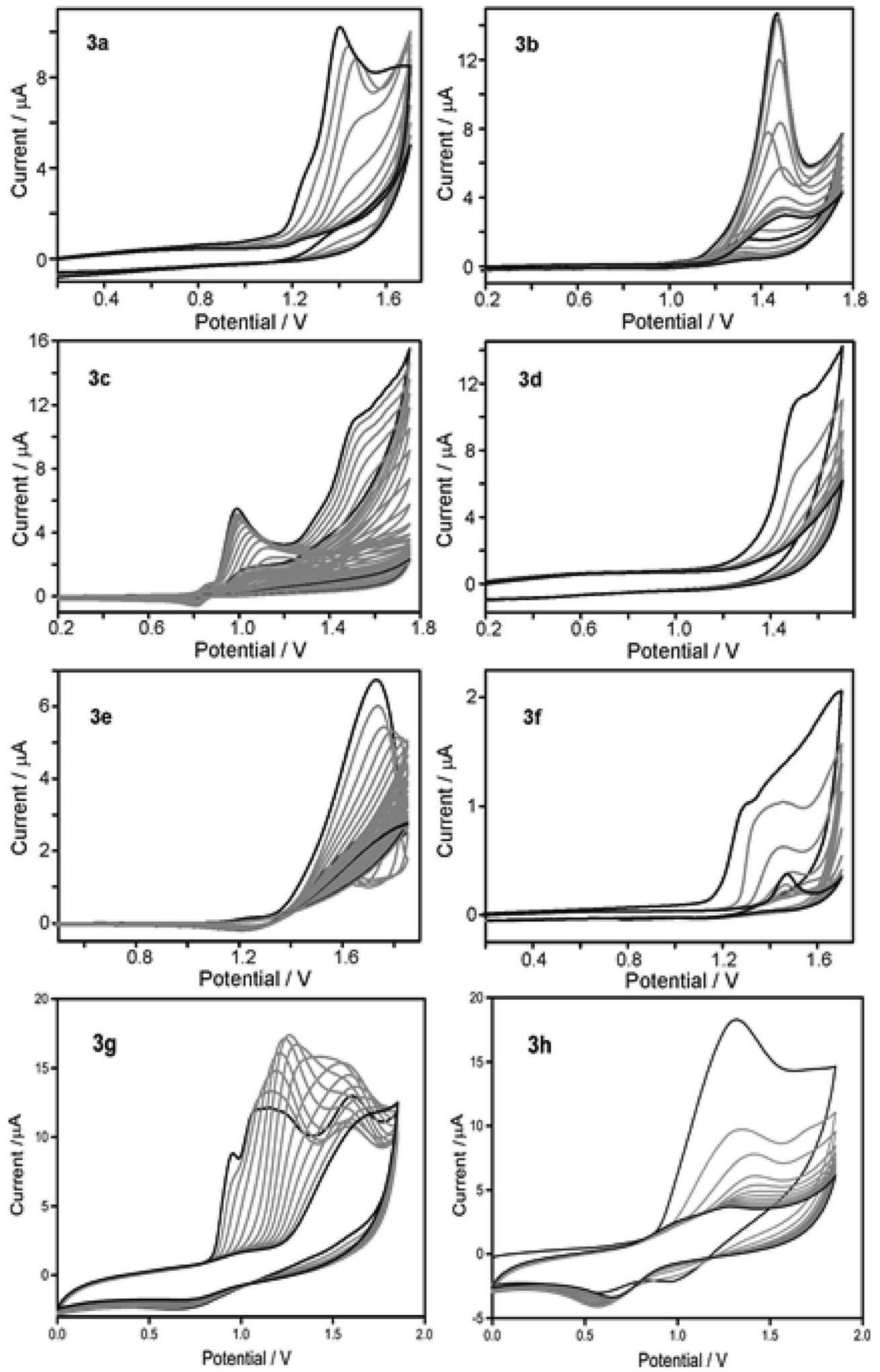

Fig. 1 Potentiodynamic electropolymerisation of $3 a-h$ against $\mathrm{Ag} / \mathrm{AgCl}$ on $\mathrm{GC}$ electrode using $n \mathrm{Bu}_{4} \mathrm{NPF}_{6}(0.1 \mathrm{M})$ in $\mathrm{CH}_{2} \mathrm{Cl}_{2}$.

revealed islands of globular lumps with irregularities whose sizes were in the range of 200-400 $\mathrm{nm}$. Finally, polymers $\mathbf{4 g}$ and 4h showed well defined porous network and uneven microporous layer respectively. In continuation, surface morphology of the synthesized polymers was probed by atomic force microscopy (AFM) by measuring the thickness of deposited polymer on ITO electrode. The corresponding three dimensional topographic images and height profile analysis were depicted in 

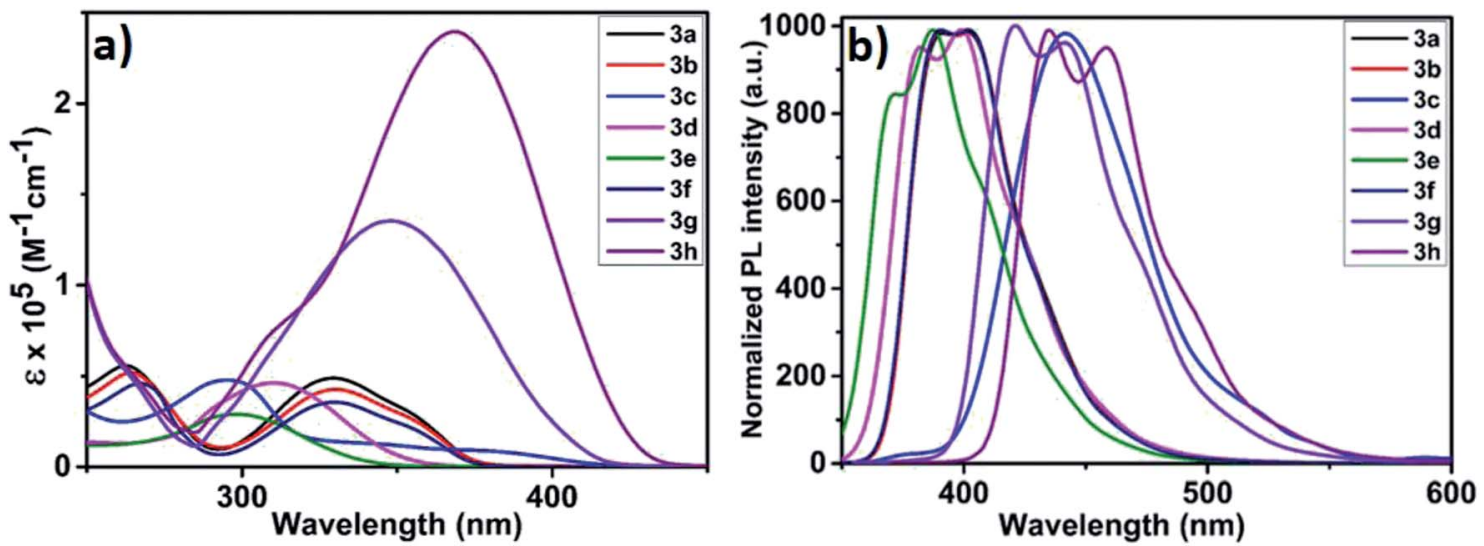

Fig. 2 (a) UV-visible absorption spectra of $3 a-h$ in THF solution $\left(5 \times 10^{-5} \mathrm{M}\right)$; (b) normalized emission spectra of $3 a-h$ in THF solution.

Fig. S8. $\uparrow$ Analysis of the images revealed that polymers derived from linear alkyl chain carbazole units showed maximum thickness $(\mathbf{4 a}=\sim 0.2 \mu \mathrm{m} ; \mathbf{4} \mathbf{f}=\sim 0.1 \mu \mathrm{m})$ compared to the branched chain analogue $(\mathbf{4 b}=\sim 0.05 \mu \mathrm{m})$. This could possibly due to the enhanced solubility of $\mathbf{4 b}$ in THF leading to weak deposition. In a similar vein, polymer with biphenyl backbone $(4 \mathbf{e}=\sim 0.2 \mu \mathrm{m})$ deposited well than the phenyl counterpart (4d $=\sim 0.1 \mu \mathrm{m})$. However, azulene polymer $4 \mathbf{c}$ showed uneven deposition with a thickness of $\sim 0.1 \mu \mathrm{m}$. In the case of thienyl polymers $4 \mathrm{~g}$ and $\mathbf{4 h}$, the thickness ranges from 0.15 to $0.22 \mu \mathrm{M}$. The thickness variation in the electrodeposited polymers may be because of the dissimilarities in the monomer concentration and solubility.

\section{Electrochemical reduction of nitrobenzene}

Reduction of nitrobenzene and its derivatives has industrial importance as it involves hazardous waste treatment. ${ }^{12 e}$ The reduction of nitrobenzene yields aniline derivatives which are mainly used as synthetic precursors for pharmaceutical products. The catalytic activities of the electro-polymers $\mathbf{4 a - h}$ were explored for the electrochemical reduction of nitrobenzene. These polymers are expected to show semi-conducting behaviour; therefore their conductivity is enhanced by doping with molecular iodine. Electrodes for nitrobenzene reduction were prepared by performing the electropolymerisation of monomers 3a-h in the presence of iodine (multiscan CV, $50 \mathrm{mV} \mathrm{s}^{-1}$, 10 cycles on GC electrode). The resulting polymer modified electrodes were then washed with distilled water and tested for catalytic activity towards the reduction of nitrobenzene in

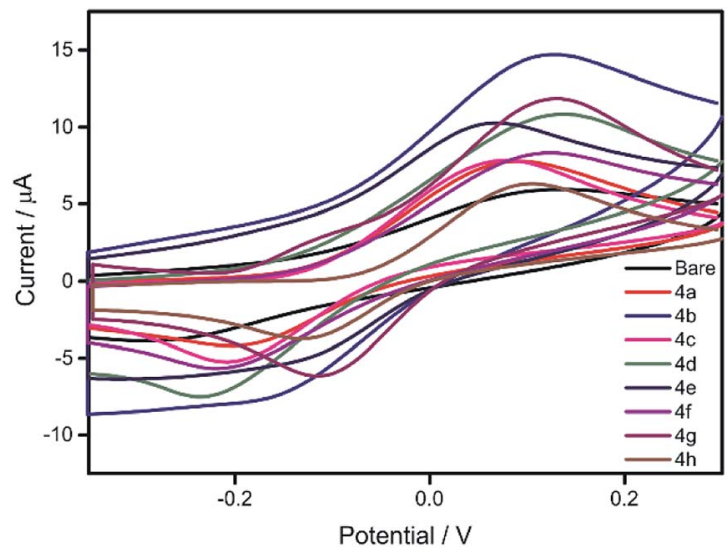

Fig. 3 Reduction of nitrobenzene on GC and polymer modified GC electrodes in PBS.

Table 2 Optical properties of monomers $3 a-f$

\begin{tabular}{|c|c|c|c|c|c|c|c|c|c|c|}
\hline Monomer & $\begin{array}{l}\lambda_{\max }{ }^{a} / \lambda_{\text {edge }} \\
(\mathrm{nm})\end{array}$ & $\varepsilon\left(\mathrm{M}^{-1} \mathrm{~cm}^{-1}\right)$ & $E_{\mathrm{g}}^{\mathrm{opt} b}(\mathrm{eV})$ & $\begin{array}{l}\lambda_{\max }{ }^{c} / \lambda_{\text {edge }} \\
(\mathrm{nm})\end{array}$ & $E_{\mathrm{g}}^{\mathrm{opt} d}(\mathrm{eV})$ & $\lambda_{\mathrm{em}}{ }^{e}(\mathrm{~nm})$ & $\begin{array}{l}\text { Stokes }{ }^{f} \\
\text { shift }\left(\mathrm{cm}^{-1}\right)\end{array}$ & Polymer & $\begin{array}{l}\lambda_{\text {max }} / \lambda_{\text {edge }} \\
(\mathrm{nm})\end{array}$ & $E_{\mathrm{g}}^{\mathrm{opt} b}(\mathrm{eV})$ \\
\hline $3 a$ & $329 / 374$ & 49200 & 3.31 & $335 / 384$ & 3.22 & 403 & 5600 & $4 a$ & $461 / 579$ & 2.14 \\
\hline $3 c$ & $295 / 417$ & 48000 & 2.97 & $302 / 425$ & 2.91 & 442 & 11300 & $4 c$ & $373 / 433$ & 2.86 \\
\hline $3 d$ & $309 / 352$ & 46500 & 3.52 & $309 / 389$ & 3.18 & 398 & 7200 & 4d & $462 / 577$ & 2.14 \\
\hline $3 e$ & $298 / 338$ & 29000 & 3.66 & $302 / 349$ & 3.55 & 387 & 7700 & $4 e$ & $460 / 581$ & 2.13 \\
\hline $3 \mathbf{h}$ & $368 / 422$ & 239900 & 2.93 & $415 / 527$ & 2.35 & 458 & 5300 & $4 h$ & $429 / 534$ & 2.32 \\
\hline
\end{tabular}

${ }^{a}$ Absorption in solution. ${ }^{b}$ Band gap in solution was determined from $\lambda_{\text {edge }}$ using, $E_{\mathrm{g}}^{\mathrm{opt}}(\mathrm{eV}) 1240 / \lambda_{\text {edge }}{ }^{c}$ Absorption in thin films. ${ }^{d}$ Optical band gap was determined from $\lambda_{\text {edge }}$ in thin solid films using, $E_{\mathrm{g}}^{\mathrm{opt}}(\mathrm{eV})=1240 / \lambda_{\text {edge. }}{ }^{e}$ Emission in solution. ${ }^{f}$ Stokes shift was calculated from the difference between $\lambda_{\max }$ and $\lambda_{\mathrm{em}}$. 
phosphate buffer solution (PBS). The results are compared with that obtained for bare GC electrode as shown in Fig. 3. It is worth mentioning that the polymer modified GC electrodes showed better onset potential and current intensity compared to bare GC, thus highlights their superior catalytic activity than GC electrodes. Among the tested electrodes, the one with polymer $\mathbf{4 b}$ exhibited excellent catalytic activity followed by $\mathbf{4 d}$, 4g, 4e, 4f, 4c, $4 \mathrm{a}$ and $4 \mathrm{~h}$.

In order to investigate the effect of scan rate on peak currents, CV was recorded at various scan rates using polymer ( $4 \mathrm{~g}$ and $\mathbf{4 h}$ ) modified GC electrode. The scan rate dependence of both cathodic reduction and anodic oxidation are shown in Fig. S9. $\uparrow$ A linear variation was observed for potential scan rates from 20 to $250 \mathrm{mV} \mathrm{s}^{-1}$ signifying that the electroactive species is involved in the reaction. ${ }^{17}$ With an increase in scan rate, oxidation is shifted towards positive potential and the reduction towards negative potential which is indicative of the kinetic limitations of the reduction process. With an increase in scan rate, all peak currents varied linearly which signifies a typical diffusion-controlled electrochemical process. Further investigations on improving the conductivity and electrochemical performance by fine tuning with other dopants are actively underway.

\section{Experimental section}

\section{Materials, methods and measurements}

All commercially available reagents were used without further purification unless otherwise stated. Solutions in organic solvents were dried with anhydrous sodium sulphate. Solvents were evaporated under reduced pressure. Column chromatography was performed using thick-walled glass columns along with a mixture of petroleum ether and ethyl acetate on silica gel (100-200 mesh, SRL, India). The relative proportions of solvents in chromatography solvent mixtures refer to the volume to volume ratio. Analytical TLC was performed on precoated plastic sheets of silica gel G/UV-254 of $0.2 \mathrm{~mm}$ thickness (Macherey-Nagel, Germany) using analytical grade solvents and visualized with iodine spray ( $10 \% \mathrm{w} / \mathrm{w} \mathrm{I}_{2}$ in silica gel), UV light ( $\lambda$ $=254$ and $365 \mathrm{~nm}$ ) and alkaline $\mathrm{KMnO}_{4}$ solution. Melting points were recorded on micro controller based melting point apparatus using open capillaries. Infrared (IR) spectra for all solid compounds were recorded on a Bruker Optik $\mathrm{GmbH}$, TENSOR 27 FT-IR spectrophotometer as KBr pellets. ${ }^{1} \mathrm{H}$ and ${ }^{13} \mathrm{C}$ NMR spectra were obtained in benzene- $d_{6}$ and $\mathrm{CDCl}_{3}$ on a BRUKER spectrometer at 400, 500 and 100, $125 \mathrm{MHz}$ respectively. Proton chemical shifts $(\delta)$ are relative to tetramethylsilane (TMS, $\delta=0.00$ ) as internal standard and expressed in parts per million. The number of protons $(n)$ for a given resonance was indicated as $\mathrm{nH}$. Spin multiplicities are given as s (singlet), $\mathrm{d}$ (doublet), t (triplet), q (quartet) and m (multiplet). Coupling constants $(J)$ are given in hertz. Dihalo precursors are prepared following standard procedures ${ }^{\mathbf{1 8}}$ and procured from SigmaAldrich. UV-visible spectra were measured as chloroform solution and thin film on SHIMADZU UV-3600 spectrophotometer. Cyclic voltammetry (CV) experiments were performed with Autolab potentiostat-galvanostat (Model PGSTAT-30). All CV measurements were carried out at room temperature with a three-electrode configuration employing glassy carbon as working electrode, silver/silver nitrate as reference electrode, and platinum as counter electrode. Degassed acetonitrile or dichloromethane was used as medium with tetrabutylammonium hexafluorophosphate $(0.1 \mathrm{M})$ as the supporting electrolyte at a scan rate of $50 \mathrm{mV} \mathrm{s}^{-1}$. Atomic force microscopic images were captured using 5500 series, Agilent Technologies.

\section{General experimental procedure for the synthesis of $3 a-h$}

1.0 eq. of dihalo compound (1a-h) was dissolved in $25 \mathrm{~mL}$ of toluene. To this mixture, 2.2 eq. of 3-hexylthiopheneboronic acid pinacol ester (2) and $20 \mathrm{~mL}$ of $2 \mathrm{M} \mathrm{K}_{2} \mathrm{CO}_{3}$ solution were added one another in the interval of $10 \mathrm{~min}$ under argon medium. Then 5 mol\% of $\left(\mathrm{Ph}_{3} \mathrm{P}\right)_{4} \mathrm{Pd}$ was added 1 hour deferred from the prerequisite addition and then refluxed for $24 \mathrm{~h}$. The crude product was extracted with chloroform and water. The organic fraction was concentrated under reduced pressure and then chromatographed on silica column (100-200 mesh) using $5 \%$ EA/PE as an eluent. Pure monomer (3a-h) was obtained.

9-Hexyl-2,7-bis(3-hexylthiophen-2-yl)-9H-carbazole (3a). (2.41 g, 95\%), bright yellow solid; $\mathrm{mp} 48-50{ }^{\circ} \mathrm{C} ; R_{\mathrm{f}}=0.17$ (PE); IR (KBr): $\nu=2923,2855,1599,1457,1327,1176,854,804,724$, $661 \mathrm{~cm}^{-1} ;{ }^{1} \mathrm{H}$ NMR (400 MHz, $\left.\mathrm{C}_{6} \mathrm{D}_{6}\right): \delta=0.77-0.90(\mathrm{~m}, 9 \mathrm{H})$, 0.99-1.11 (m, 6H), 1.16-1.31 (m, 12H), 1.49-1.56 (m, 2H), 1.60$1.68(\mathrm{~m}, 4 \mathrm{H}), 2.80(\mathrm{t}, J=8.0 \mathrm{~Hz}, 4 \mathrm{H}), 3.80(\mathrm{t}, J=8.0 \mathrm{~Hz}, 2 \mathrm{H}), 6.92$ $(\mathrm{d}, J=4.0 \mathrm{~Hz}, 2 \mathrm{H}), 7.01(\mathrm{~d}, J=4.0 \mathrm{~Hz}, 2 \mathrm{H}), 7.48(\mathrm{~d}, 1 \mathrm{H}), 7.50$ (d, $1 \mathrm{H}), 7.51(\mathrm{~s}, 2 \mathrm{H}), 7.95-7.97(\mathrm{~d}, J=8.0 \mathrm{~Hz}, 2 \mathrm{H}) ;{ }^{13} \mathrm{C}$ NMR $(100$ $\left.\mathrm{MHz}, \mathrm{C}_{6} \mathrm{D}_{6}\right): \delta=13.8,13.9,22.4,22.6,26.9,28.8,28.9,31.2,31.4$, 31.7, 42.6, 109.7, 120.5, 121.1, 122.3, 123.6, 128.3, 129.4, 132.6, 138.5, 139.2, 141.2; HRMS $\mathrm{m} / z$ calculated for $\mathrm{C}_{38} \mathrm{H}_{49} \mathrm{NS}_{2} \mathrm{MW}$ : 583.3306 , found: 583.3304 .

9-(2-Ethylhexyl)-2,7-bis(3-hexylthiophen-2-yl)-9H-carbazole (3b). (1.31 g, 94\%), bright yellow semi solid, $R_{\mathrm{f}}=0.12(\mathrm{PE})$; IR (KBr): $\nu=2926,2859,2400,2312$, 1737, 1602, 1456, 1327, 1247, $807,720,657 \mathrm{~cm}^{-1} ;{ }^{1} \mathrm{H}$ NMR (400 $\left.\mathrm{MHz}, \mathrm{CDCl}_{3}\right): \delta=0.74-0.78$ $(\mathrm{m}, 10 \mathrm{H}), 0.84(\mathrm{t}, J=7.2 \mathrm{~Hz}, 4 \mathrm{H}), 1.16-1.16(\mathrm{~m}, 13 \mathrm{H}), 1.32(\mathrm{t}, J=$ $7.2 \mathrm{~Hz}, 3 \mathrm{H}), 1.54-1.61(\mathrm{~m}, 5 \mathrm{H}), 2.03(\mathrm{t}, J=6 \mathrm{~Hz}, 1 \mathrm{H}), 2.67(\mathrm{t}, J=$ $7.6 \mathrm{~Hz}, 5 \mathrm{H}), 4.11\left(\mathrm{dd}, J_{1}=2.0 \mathrm{~Hz}, J_{2}=7.2 \mathrm{~Hz}, 2 \mathrm{H}\right), 6.95(\mathrm{~d}, J=$ $5.2 \mathrm{~Hz}, 3 \mathrm{H}), 7.20(\mathrm{~s}, 1 \mathrm{H}), 7.23(\mathrm{~d}, J=1.6 \mathrm{~Hz}, 1 \mathrm{H}), 7.25(\mathrm{~d}, J=$ $1.6 \mathrm{~Hz}, 1 \mathrm{H}), 7.36(\mathrm{~d}, J=0.8 \mathrm{~Hz}, 2 \mathrm{H}), 8.01(\mathrm{~d}, J=8.0 \mathrm{~Hz}, 2 \mathrm{H}) ;{ }^{13} \mathrm{C}$ NMR (100 MHz, CDCl3): $\delta=9.9,12.9,13.0,21.6,22.0,23.44$, 27.7, 27.9, 28.3, 28.6, 30.1, 30.6, 38.4, 46.6, 108.8, 119.1, 119.8, $120.7,122.5,128.5,131.2$, 137.4, 137.9, 140.4; HRMS $m / z$ calculated for $\mathrm{C}_{40} \mathrm{H}_{53} \mathrm{NS}_{2}$ MW: 611.3619 , found: 611.3611 .

1,3-Bis(3-hexylthiophen-2-yl)azulene (3c). (123.2 mg, 92\%), dark blue semi solid; $R_{\mathrm{f}}=0.23$ (PE); IR (KBR): $\nu=3058,2925$, 2856, 1732, 1570, 1456, 1401, 1220, 1088, 946, 870, 729, 652, $574 \mathrm{~cm}^{-1} ;{ }^{1} \mathrm{H}$ NMR $\left(500 \mathrm{MHz}, \mathrm{CDCl}_{3}\right) \delta=0.68(\mathrm{t}, J=10.0 \mathrm{~Hz}$, $6 \mathrm{H}), 1.02-1.17(\mathrm{~m}, 12 \mathrm{H}), 1.43-1.49(\mathrm{~m}, 4 \mathrm{H}), 2.47(\mathrm{t}, J=10.0 \mathrm{~Hz}$, $4 \mathrm{H}), 7.00(\mathrm{~d}, J=5 \mathrm{~Hz}, 4 \mathrm{H}), 7.05(\mathrm{t}, J=10.0 \mathrm{~Hz}, 2 \mathrm{H}), 7.25(\mathrm{~d}, J=$ $5.1 \mathrm{~Hz}, 2 \mathrm{H}), 7.49$ (d, $J=10.0 \mathrm{~Hz}, 2 \mathrm{H}), 7.84(\mathrm{~s}, 1 \mathrm{H}), 8.29$ (d, $J=$ $10.0 \mathrm{~Hz}, 2 \mathrm{H}) ;{ }^{13} \mathrm{C} \mathrm{NMR}\left(125 \mathrm{MHz}, \mathrm{CDCl}_{3}\right) \delta=14.0,22.6,29.0$, 29.0, 30.9, 31.64, 122.0, 123.7, 124.4, 129.0, 132.0, 136.5, 138.5, 138.9, 140.33, 140.5; HRMS $m / z$ calculated for $\mathrm{C}_{30} \mathrm{H}_{36} \mathrm{~S}_{2}$ MW: 460.2258 , found: 460.2257 . 
4,4'-Bis(3-hexylthiophen-2-yl)-1,1'-biphenyl (3d). (534 mg, 89\%), yellow solid; mp: $51-53{ }^{\circ} \mathrm{C} ; R_{\mathrm{f}}=0.17$ (PE); IR (KBR): $\nu=$ 3051, 2923, 2855, 1911, 1729, 1668, 1543, 1479, 1384, 1135, 1084, 947, 826, 688, 644, 531, $484 \mathrm{~cm}^{-1} ;{ }^{1} \mathrm{H}$ NMR $(500 \mathrm{MHz}$, $\left.\mathrm{CDCl}_{3}\right) \delta=0.78(\mathrm{t}, J=5.0 \mathrm{~Hz}, 6 \mathrm{H}), 1.19-1.27(\mathrm{~m}, 12 \mathrm{H}), 1.52-1.58$ $(\mathrm{m}, 4 \mathrm{H}), 2.62(\mathrm{t}, J=5.0 \mathrm{~Hz}, 4 \mathrm{H}), 6.91(\mathrm{~d}, J=5.0 \mathrm{~Hz}, 2 \mathrm{H}), 7.15(\mathrm{~d}, J$ $=5.0 \mathrm{~Hz}, 2 \mathrm{H}), 7.44(\mathrm{~d}, J=5.0 \mathrm{~Hz}, 4 \mathrm{H}), 7.59$ (d, $J=5.0 \mathrm{~Hz}, 4 \mathrm{H})$; ${ }^{13} \mathrm{C} \mathrm{NMR}\left(125 \mathrm{MHz}, \mathrm{CDCl}_{3}\right) \delta=14.1,22.6,28.8,29.2$, 31.0, 31.7, 123.8, 127.0, 129.7, 129.8, 134.0, 137.4, 138.9, 139.4; HRMS m/z calculated for $\mathrm{C}_{32} \mathrm{H}_{38} \mathrm{~S}_{2} \mathrm{MW}$ : 486.2415, found: 486.2410 .

1,4-Bis(3-hexylthiophen-2-yl)benzene (3e). (1.21 g, 97\%), yellow semi solid; $R_{\mathrm{f}}=0.33(\mathrm{PE})$; IR (KBR): $\nu=3063,2927,2858$, 1550, 1454, 1373, 1093, 964, 836, 718, $654 \mathrm{~cm}^{-1} ;{ }^{1} \mathrm{H}$ NMR $(500$ $\left.\mathrm{MHz}, \mathrm{CDCl}_{3}\right) \delta=0.92(\mathrm{t}, J=5.0 \mathrm{~Hz}, 6 \mathrm{H}), 1.30-1.41(\mathrm{~m}, 12 \mathrm{H})$, 1.65-1.71 (m, 4H), $2.75(\mathrm{t}, J=5.0 \mathrm{~Hz}, 4 \mathrm{H}), 7.05(\mathrm{~d}, J=5.0 \mathrm{~Hz}$, 2H), $7.29(\mathrm{~d}, J=5.0 \mathrm{~Hz}, 2 \mathrm{H}), 7.52(\mathrm{~s}, 4 \mathrm{H}) ;{ }^{13} \mathrm{C}$ NMR $(125 \mathrm{MHz}$, $\left.\mathrm{CDCl}_{3}\right) \delta=14.3,22.8,28.9,29.4,31.2,31.8,123.9,129.5,129.7$, 133.99, 137.5, 138.9; HRMS $m / z$ calculated for $\mathrm{C}_{26} \mathrm{H}_{34} \mathrm{~S}_{2}$ MW: 410.2102, found: 410.2106 .

2,7-Bis(3-hexylthiophen-2-yl)-9-octyl-9H-carbazole

(3f). $(2.73 \mathrm{~g}, 76 \%)$, pale yellow solid, $\mathrm{mp} 49-52{ }^{\circ} \mathrm{C} ; R_{\mathrm{f}}=0.12(\mathrm{PE}) ; \mathrm{IR}$ (KBR): $\nu=3064,2924,2858,1602,1563,1456,1365,1325,1251$, 1133, 1090, 847, 806, 720, $659 \mathrm{~cm}^{-1} ;{ }^{1} \mathrm{H} \mathrm{NMR}$ (400 MHz, $\mathrm{CDCl}_{3}$ ): $\delta=0.88(\mathrm{t}, J=8.0 \mathrm{~Hz}, 9 \mathrm{H}), 1.27-1.46(\mathrm{~m}, 22 \mathrm{H}), 1.65-1.73(\mathrm{~m}$, $4 \mathrm{H}), 1.89-1.96(\mathrm{~m}, 2 \mathrm{H}), 2.78(\mathrm{t}, J=8.0 \mathrm{~Hz}, 4 \mathrm{H}), 4.34(\mathrm{t}, J=8.0 \mathrm{~Hz}$, $2 \mathrm{H}), 7.06(\mathrm{~d}, J=4.0 \mathrm{~Hz}, 2 \mathrm{H}), 7.29(\mathrm{~d}, J=8.0 \mathrm{~Hz}, 2 \mathrm{H}), 7.34(\mathrm{~d}, J=$ $4.0 \mathrm{~Hz}, 1 \mathrm{H}), 7.36$ (d, $J=4.0 \mathrm{~Hz}, 1 \mathrm{H}), 7.48(\mathrm{~s}, 2 \mathrm{H}), 8.12$ (d, $J=$ 8.0 Hz, 2H); ${ }^{13} \mathrm{C}$ NMR (100 MHz, $\left.\mathrm{CDCl}_{3}\right): \delta=14.1,22.6,22.6$, $27.4,28.9,29.1,29.2,29.3,29.4,31.2,31.7,31.8,43.2,109.5$, 120.2, 120.9, 121.8, 123.6, 129.6, 132.3, 138.6, 138.9, 141.0; HRMS $\mathrm{m} / \mathrm{z}$ calculated for $\mathrm{C}_{40} \mathrm{H}_{53} \mathrm{NS}_{2}$ MW: 611.3619, found: 611.3613 .

2,5-Bis(3-hexylthiophen-2-yl)thieno[3,2-b]thiophene (3g). (1.11 g, 82\%), green semisolid, $R_{\mathrm{f}}=0.64$ (5\% EA/PE), IR (KBR): $\nu$ $=3084,2979$, 2843, 2721, 2339, 1731, 1625, 1541, 1459, 1393, 1177, 1088, 918, 814, $692 \mathrm{~cm}^{-1} ;{ }^{1} \mathrm{H}$ NMR (500 MHz, $\mathrm{CDCl}_{3}, \delta$ in ppm): $0.81(\mathrm{t}, 6 \mathrm{H}, J=5.0 \mathrm{~Hz}), 1.18-1.31(\mathrm{~m}, 13 \mathrm{H}), 1.51-1.61(\mathrm{~m}$, $4 \mathrm{H}), 2.71(\mathrm{t}, 3 \mathrm{H}, J=5.0 \mathrm{~Hz}), 6.89(\mathrm{~d}, 2 \mathrm{H}, J=5.0 \mathrm{~Hz}), 7.14(\mathrm{~d}, 2 \mathrm{H}, J$ $=5.0 \mathrm{~Hz}), 716(\mathrm{~s}, 2 \mathrm{H}) ;{ }^{13} \mathrm{C} \mathrm{NMR}\left(125 \mathrm{MHz}, \mathrm{CDCl}_{3}, \delta\right.$ in ppm): 14.0, 22.6, 29.2, 30.8, 31.7, 118.0, 124.3, 130.0, 130.7, 137.6, 139.1, 140.3; HRMS $m / z$ calculated for $\mathrm{C}_{26} \mathrm{H}_{32} \mathrm{~S}_{4}$ MW: 472.1387, found: 472.1384 .

2,6-Bis(3-hexylthiophen-2-yl)dithieno[3,2-b:2', $\left.3^{\prime}-d\right]$ thiophene (3h). (0.63 g, 85\%), yellow solid, mp $160-165{ }^{\circ} \mathrm{C} ; R_{\mathrm{f}}=0.61(5 \%$ $\mathrm{EA} / \mathrm{PE})$, IR (KBR): $\nu=3092,2934,2869,2382,1750,1661,1583$, 1471, 1423, 1373, 1245, 1181, 1093, 907, 811, 699, $607 \mathrm{~cm}^{-1} ;{ }^{1} \mathrm{H}$ NMR (500 MHz, $\mathrm{CDCl}_{3}, \delta$ in ppm): $0.9(\mathrm{t}, 6 \mathrm{H}, J=5.0 \mathrm{~Hz}), 1.32-$ $1.42(\mathrm{~m}, 12 \mathrm{H}), 1.69(\mathrm{p}, 4 \mathrm{H}, J=5.0 \mathrm{~Hz}), 2.83(\mathrm{t}, 4 \mathrm{H}, J=10.0 \mathrm{~Hz})$, $6.99(\mathrm{~d}, 2 \mathrm{H}, J=5.0 \mathrm{~Hz}), 7.24(\mathrm{~d}, 2 \mathrm{H}, J=5.0 \mathrm{~Hz}), 7.31(\mathrm{~s}, 2 \mathrm{H}) ;{ }^{13} \mathrm{C}$ NMR (125 MHz, $\mathrm{CDCl}_{3}, \delta$ in ppm): 14.0, 22.6, 29.2, 29.2, 30.7, 31.6, 119.2, 124.4, 130.1 130.5, 130.6, 136.9, 140.3, 140.9; HRMS $m / z$ calculated for $\mathrm{C}_{28} \mathrm{H}_{32} \mathrm{~S}_{5}$ MW: 528.1108, found: 528.1101.

\section{Conclusions}

Comonomers end-capped with thienyl units were successfully prepared via Suzuki-Miyaura coupling reaction in synthetically excellent yields. Potentiodynamic electropolymerisation of these monomers on ITO substrate afforded thin films of electrodeposited $\pi$-conjugated polymers between 0.05 and $0.2 \mu \mathrm{M}$. Microstructure of the polymers revealed different surface morphology and porosity. The electrochemically synthesized polymers were found to exhibit excellent catalytic activity in the reduction of nitrobenzene than bare GC electrode. Further studies to delineate the scope of our monomers and polymers for other applications are on the way.

\section{Conflicts of interest}

There are no conflicts to declare.

\section{Acknowledgements}

Financial support by the Department of Science \& Technology (DST), India to carry out this work through INSPIRE faculty award (IFA-14/MS-27) and (IFA-13/CH-133) is greatly acknowledged.

\section{Notes and references}

1 X. Guo, M. Baumgarten and K. Müllen, Prog. Polym. Sci., 2013, 38, 1832.

2 A. Facchetti, Chem. Mater., 2011, 23, 733.

3 (a) J. Roncali, Chem. Rev., 1997, 97, 173; (b) Y.-J. Cheng, S.-H. Yang and C.-S. Hsu, Chem. Rev., 2009, 109, 5868.

4 (a) I. Salzmann, G. Heimel, M. Oehzelt, S. Winkler and N. Koch, Acc. Chem. Res., 2016, 49, 370; (b) B. Lüssem, C.-M. Keum, D. Kasemann, B. Naab, Z. Bao and K. Leo, Chem. Rev., 2016, 116, 13714.

5 B. B. Berkes, A. S. Bandarenka and G. Inzelt, J. Phys. Chem. C, 2015, 119, 1996.

6 (a) Q. Zhang, H. Dong and W. Hu, J. Mater. Chem. C, 2018, 6, 10672; (b) Electropolymerization: Concepts, Materials and Applications, ed. S. Cosnier and A. Karyakin, WILEY-VCH Verlag GmbH \& Co. KGaA, Weinheim, 2010.

7 Electropolymerization: Concepts, Materials and Applications, ed. S. Cosnier and A. Karyakin, WILEY-VCH Verlag GmbH \& Co. KGaA, Weinheim, 2010.

8 C. A. Ferreira, S. Aeiyach, M. Delamer and P. C. Lacaze, J. Electroanal. Chem., 1990, 284, 351.

9 E. Poverenov, M. Li, A. Bitler and M. Bendikov, Chem. Mater., 2010, 22, 4019.

10 B. Lu, S. Zhen, S. Ming, J. Xu and G. Zhao, $R S C A d v .$, 2015, 5, 70649.

11 J. A. Carrillo, M. J. Ingleson and M. L. Turner, Macromolecules, 2015, 48, 979.

12 (a) A. A. Raheem, S. Kamaraj, V. Sannasi and C. Praveen, Org. Chem. Front., 2018, 5, 777; (b) S. Gopi, K. Giribabu and M. Kathiresan, ACS Omega, 2018, 3, 6251; (c) K. Madasamy, V. M. Shanmugam, D. Velayutham and M. Kathiresan, Sci. Rep., 2018, 8, 1354; (d) M. Kathiresan, H.-J. Steinhoff and L. Walder, Macromol. Chem. Phys., 2017, 218, 1700142; (e) S. Gopi and M. Kathiresan, Polymer, 2017, 109, 315; (f) 
K. Madasmy and M. Kathiresan, ChemistrySelect, 2016, 3, 354.

13 (a) S. Koyuncu, O. Usluer, M. Can, S. Demic, S. Icli and N. S. Sariciftci, J. Mater. Chem., 2011, 21, 2684; (b) F. B. Koyuncu, S. Koyuncu and E. Ozdemir, Org. Electron., 2011, 12, 1701; (c) F. B. Koyuncu, S. Koyuncu and E. Ozdemir, Electrochim. Acta, 2010, 55, 4935.

14 E. Amir, M. Murai, R. J. Amir, J. S. Cowart Jr, M. L. Chabinyc and C. J. Hawker, Chem. Sci., 2014, 4, 4483.

15 (a) T.-J. Lin and S.-T. Lin, Phys. Chem. Chem. Phys., 2015, 17, 4127; (b) H. Huang, L. Yang, A. Facchetti and T. J. Marks, Chem. Rev., 2017, 117, 10291.
16 E. Amir, R. J. Amir, L. M. Campos and C. J. Hawker, J. Am. Chem. Soc., 2011, 133, 10046.

17 W. Richard, D. Evrard and P. Gros, J. Electroanal. Chem. Interfacial Electrochem., 2012, 685, 109.

18 (a) T.-H. Lee, K.-Y. Wu, T.-Y. Lin, J.-S. Wu, C.-L. Wang and C.-S. Hsu, Macromolecules, 2013, 46, 7687; (b) H. Wakabayashi, T. Kurihara, K. Shindo, M. Tsukada, P.-W. Yang, M. Yasunami and T. Nozoe, J. Chin. Chem. Soc., 1998, 45, 391. 